\title{
As Dimensões da Sustentabilidade Aplicadas em uma Indústria de Alimentos na Cidade de Juazeiro do Norte-CE
}

\author{
Edina de Oliveira Sineis ${ }^{1}$; Joyce da Silva Albuquerque ${ }^{2}$
}

Resumo: A sustentabilidade possui três dimensões que visam relaciona-se com o contexto empresarial, por isto o presente artigo tem por objetivo relacionar as dimensões da sustentabilidade às práticas produtivas de uma indústria de alimentos. De forma metodológica, possui uma pesquisa com abordagem qualitativa, descritiva e exploratória. A coleta de dados ocorreu por meio de uma entrevista que foi aplicada ao gestor de uma indústria alimentícia, localizada na cidade de Juazeiro do Norte-Ceará. O instrumento de coleta aconteceu por intermédio de um questionário com 20 perguntas abertas, em seguida ocorreu à análise dos dados obtidos. Como resultado, notouse que a empresa trabalha de maneira parcial com as três dimensões da sustentabilidade, em especial com a social. Percebeu-se também que dimensão ambiental está bem presente, pois existe a preocupação com a qualidade dos produtos ofertados aos clientes.

Palavras Chave: Sustentabilidade Empresarial. Dimensões. Indústria.

\section{The Dimensions of Sustainability Applied to a Food Industry in the City of Juazeiro do Norte in the State of Ceará}

\begin{abstract}
The sustainability possesses three dimensions that seek links with the business context, for this the present article has for objective to relate the dimensions of the sustainability to the productive practices of an industry of foods. In a methodological way, it possesses a research with approach qualitative, descriptive and exploratory. The collection of data happened through an interview that was applied the manager of a provision industry, located in the city of Juazeiro of North-Ceará. The collection instrument happened through a questionnaire with 20 open questions, soon afterwards it happened to the analysis of the obtained data.As result, was noticed that the company works in a partial way with the three dimensions of the sustainability, especially with the social. It was also noticed that environmental dimension is very present, because the concern exists with the quality of the products presented to the customers.
\end{abstract}

Keywords: Business Sustainability. Dimensions. Industry.

\section{Introdução}

Na plenitude da evolução, com a formação das espécies, a natureza tem oferecido tudo que é necessário para sobrevivência dos seres vivos existentes, porém com o aumento da

\footnotetext{
${ }^{1}$ Graduanda em Administração, Centro Universitário Doutor Leão Sampaio, Juazeiro do Norte, Ceará, Brasil. Contato: edinha.20@ hotmail.com;

${ }^{2}$ Mestre em Administração de Empresas. Centro Universitário Doutor Leão Sampaio, Juazeiro do Norte, Ceará, Brasil. Contato: joyce@leaosampaio.edu.br.
} 
população, acessão do capitalismo e concomitantemente da tecnologia, a exploração e devastação fez-se presente, gerando impactos ambientais que vêm crescendo bravamente nas últimas décadas, provindos das ações errônea da humanidade (SABINO 2010).

Diante da degradação do planeta e escassez de recursos naturais, começaram as primeiras preocupações com a preservação do meio ambiente, por intermédio do desenvolvimento sustentável, surgindo a partir da revolução industrial, devido à ocorrência de mudanças climáticas em função ao aumento gradativo da produção global, que vêm impactando e contaminando os recursos naturais ainda existentes, em virtude deste fato questões são levantadas acerca de produzir eficientemente em paralelo às limitações do planeta (DIAS, 2011).

A sustentabilidade contempla a racionalidade no manuseio dos recursos naturais, que prediz tanto à utilização destes recursos no presente, quanto à preservação para o futuro de forma equilibrada (BARBIERI, 2011). O desenvolvimento sustentável é aquele que supri as gerações presentes sem comprometer a qualidade de vida das gerações futuras (DIAS, 2011).

Barbieri (2011) defende que existe a sustentabilidade empresarial, voltada para a preocupação com a sociedade, auxilio na resolução dos problemas ambientais, satisfação das necessidades dos clientes e contribuição para economia do país. A sustentabilidade possui dimensões aplicadas ao contexto organizacional que pauteiam a possibilidade de alinhar os processos produtivos ao desenvolver sustentavelmente, seja no contexto social, econômico e sustentável, em especial nas indústrias alimentícias (SACHS, 2007).

Diante do exposto se questiona: Como uma indústria de alimentos pode alinhar as dimensões da sustentabilidade dentro do contexto fabril? Para responder esta problemática, este artigo objetiva de modo geral, relacionar as dimensões da sustentabilidade às práticas produtivas de uma indústria de alimentos. Especificando em identificar as práticas ambientais em uma indústria de alimentos; apresentar as dimensões da sustentabilidade propostas por Sachs no contexto de uma indústria de alimentos; analisar a performance de uma indústria alimentícia, sob a ótica da sustentabilidade empresarial.

Este artigo torna-se relevante, pois visa alinhar sustentabilidade dentro dos processos industriais no ramo alimentício, justificando-se por uma natureza social, ao proporcionar melhorias na conduta e responsabilidade na produção fabril. Em termos acadêmicos, destacase por gerar informações importantes sobre a sustentabilidade empresarial e suas dimensões, 
sendo então uma fonte de pesquisa aos leitores, visto que não há muitas publicações que visem o alinhamento das dimensões da sustentabilidade em indústrias de alimentos.

\section{Fundamentação Teórica}

\section{Desenvolvimento Sustentável}

A exploração dos recursos naturais para a produção e consumo, intensificou-se ao decorrer do tempo, advindas com o avanço da tecnologia e expansão do capitalismo, oriundas desde a Revolução Industrial (SABINO, 2010). A forma, muitas vezes errônea, do homem utilizar a biodiversidade para a sobrevivência, passou a provocara consequências a natureza, por exemplo, extinção em algumas regiões da fauna e flora, desertificação, aquecimento do planeta, poluição e escassez de água em vários países (NOBREGA, 2013).

Indústrias e empresas no auge do consumismo, com produções em larga escala, sentenciam ao meio ambiente uma exploração avassaladora, não calculando a possibilidade de uma escassez de recursos naturais no futuro, visto que a biodiversidade é limitada (PHILIPPE, 2010). A preocupação com o uso inconsciente dos recursos naturais, geraram muitos estudos e conferências, que almejam um equilíbrio entre produção e meio ambiente, levando em consideração os inúmeros impactos ambientais resultantes da negligência de empresas, governos e pessoas ao manusear as riquezas naturais em todo o planeta (NOBREGA, 2013).

$\mathrm{Na}$ perspectiva de sanar os problemas ambientais, movimentos globais para alinhar e promover um desenvolvimento sustentável foram dialogadas em vários países, destacando as discursões para criar uma consciência sobre sustentabilidade (DIAS, 2011). O quadro 01 resume alguns dos marcos históricos da sustentabilidade e receptivas contribuições. 
Quadro 01: Marcos Históricos da Sustentabilidade.

\begin{tabular}{|c|c|}
\hline Marco Histórico & Contribuição \\
\hline $\begin{array}{l}\text { Publicação do Livro } \\
\text { Primavera Silenciosa } \\
\text { Rachel Carson } \\
\text { (1962) }\end{array}$ & $\begin{array}{l}\text { Mensurava conhecimento sobre os malefícios causados pelos pesticidas químicos, } \\
\text { quanto à utilização na produção de alimentos, defendendo meios de controles } \\
\text { alternativos na detenção de pragas. A ideologia não agradou os produtores e } \\
\text { empresários da época, todavia foi o passo inicial para a formulação do conceito e } \\
\text { aplicabilidade do desenvolvimento sustentável. }\end{array}$ \\
\hline $\begin{array}{l}\text { Estocolmo } \\
\text { (1972) }\end{array}$ & $\begin{array}{l}\text { O primeiro evento organizado pela Organização das Nações Unidas (ONU) para } \\
\text { discutir de maneira global as questões ambientais. Foi criado um documento } \\
\text { intitulado Declaração sobre o Meio Ambiente Humano, que constava princípios de } \\
\text { conduta socioambiental. }\end{array}$ \\
\hline $\begin{array}{l}\text { Agenda-21 } \\
\text { (1992) }\end{array}$ & $\begin{array}{l}\text { Aprovada durante a Conferência das Nações Unidas sobre o Meio Ambiente e } \\
\text { Desenvolvimento Humano, constituiu na criação de um plano de ação para ser } \\
\text { adotado em escala global, nacional e local por organizações, governos e sociedade } \\
\text { civil, sobre as áreas que a ação humana impacta o meio ambiente. }\end{array}$ \\
\hline $\begin{array}{l}\text { Carta da Terra } \\
\text { (1997) }\end{array}$ & $\begin{array}{l}\text { Surgiu como resposta às ameaças que se instalam sobre o planeta, buscando pensar } \\
\text { articuladamente os muitos problemas socioambientais, tendo como referência } \\
\text { central a Terra. Equiparava à Declaração Universal dos Direitos Humanos, no } \\
\text { tocante a sustentabilidade, justiça econômica, ética e paz. A partir de } 2002 \text { houve a } \\
\text { transformação desta carta em um código ético universal. }\end{array}$ \\
\hline $\begin{array}{l}\text { Protocolo de Quioto } \\
\text { (1997) }\end{array}$ & $\begin{array}{l}\text { Um tratado internacional com compromissos para reduzir a emissão dos gases que } \\
\text { provocam o efeito estufa, causa do aquecimento global. O documento propõe um } \\
\text { calendário no qual os países desenvolvidos tinha a obrigação de reduzir a } \\
\text { quantidade de gases poluentes em pelo menos, } 5,2 \% \text { até } 2012 \text {. }\end{array}$ \\
\hline $\begin{array}{l}\text { Pacto Global } \\
\text { (1999) }\end{array}$ & $\begin{array}{l}\text { Iniciativa das ONU voltada para empresas, que visava conciliar práticas de gestão } \\
\text { com as novas condutas socioambientais. Criado um documento que fundamentava } \\
\text { em } 10 \text { princípios ligados aos direitos humanos, relações de trabalho, meio ambiente } \\
\text { e combate à corrupção. }\end{array}$ \\
\hline $\begin{array}{l}\text { Metas do Milênio } \\
\qquad(2000)\end{array}$ & $\begin{array}{l}\text { Documento que consolidou várias metas estabelecidas nas conferências mundiais } \\
\text { ocorridas ao longo dos anos 90, estabelecendo os Objetivos de Desenvolvimento do } \\
\text { Milênio (ODM) que deviam ser adotados pelos membros das Nações Unidas. Os } \\
\text { objetivos foram erradicar a extrema pobreza e a fome, atingir o ensino básico } \\
\text { universal, promover a igualdade de gênero e a autonomia das mulheres, reduzir a } \\
\text { mortalidade infantil, melhorar a saúde materna, combater o HIV/AIDS, malária e } \\
\text { outras doenças, garantir a sustentabilidade ambiental e estabelecer uma parceria } \\
\text { mundial para o desenvolvimento. }\end{array}$ \\
\hline $\begin{array}{l}\mathrm{RIO}+20 \\
(2012)\end{array}$ & $\begin{array}{l}\text { A Conferência das Nações Unidas sobre Desenvolvimento Sustentável, pauteou a } \\
\text { renovação do compromisso sobre o desenvolvimento sustentável. Infelizmente não } \\
\text { alcançou os resultados esperados, mas diversos acordos e ações foram } \\
\text { estabelecidos entre os países participantes como diminuição de gases poluentes, } \\
\text { aquecimento global e efeito estufa, além de ações de inclusão. }\end{array}$ \\
\hline
\end{tabular}

Fonte: Adaptação Aligleri (2011) e Sabino (2010).

É notório que cada ação apresentada no quadro 01, impulsionou para a discussão sobre a sustentabilidade no planeta, ponderando níveis sociais, econômicos e ambientais nos países desenvolvidos ou em desenvolvimento, debatendo os caminhos que a exploração frenética estava tomando, as reais consequências deste ato e a extrema necessidade da construção de um desenvolvimento sustentável (DIAS, 2011). 
Neste sentido, sustentabilidade conforme Philippe (2010) é a capacidade de se auto sustentar, manter um processo produtivo utilizando os recursos naturais disponíveis, mas agregando meios ou atividades corretas na forma de manusear determinados recursos, havendo um equilíbrio entre a necessidade em produzir e a quantidade disponível. Deste modo, partindo do pressuposto da sustentabilidade, o desenvolvimento sustentável passa a ser caracterizado como a facilidade de suprir as necessidades presentes sem afetar a habilidade das gerações futuras em suprirem as próprias necessidades (ALIGLERI, 2011).

Corroborando nesse entendimento, Sachs (2009) pontua que o desenvolvimento sustentável é capacidade de atender tanto a geração atual, quanto à futura, sem comprometer ou esgotar os recursos naturais, havendo uma harmonia entre economia e conservação ambiental. O autor defende ainda que para alcançar o desenvolvimento econômico de forma sustentável, é necessário existir um planejamento, noções da limitação da natureza, conscientização das organizações e pessoas, ações governamentais e atividades socioeconômicas com diretrizes voltadas a diversidade regional.

Barbieri (2011) destaca que na solução dos problemas ambientais ou minimização destes, os empresários e administradores, devem agir em conformidade ao desenvolvimento sustentável, adotando concepções administrativas e tecnológicas ecologicamente viáveis nos processos ou decisões, contribuindo na ampliação da capacidade de suporte do planeta nas gerações futuras.

Embora a necessidade do desenvolvimento sustentável seja latente, Veiga (2005) ressalta que se desenvolver sustentavelmente ainda é uma questão que está fora das nossas práticas habituais, visto o pouco engajamento das empresas, governos e população com as causas sustentáveis, além do aumento gradativo da população, as elevadas demandas industriais e baixos incentivos dos governos. No entanto o autor aponta que é possível alinhar economia, sociedade e ambiente, quando são desenvolvidas práticas de condutas ou inovações socioambientais, que gerem lucros, proponha qualidade de vida às pessoas e preserve a biodiversidade. 


\section{Dimensões da Sustentabilidade}

Conforme exposto no capítulo anterior, o desenvolvimento sustentável é uma necessidade que deve ser absorvido como compromisso de todos, inclusive dos governos e empresas. No contexto empresarial a sustentabilidade pode ser definida como estratégias adotadas para manter um equilíbrio entre produção e natureza (SOUZA E CORDEIRO, 2010). Tendo em vista a busca por esta harmonização, a sustentabilidade possui dimensões entrelaçadas ao desenvolvimento sustentável, no contexto ambiental, social e econômico (FREITAS, 2012).

A filosofia pregada pelas dimensões baseia-se na possibilidade de desenvolver inovações que contribuam ao bem-estar e qualidade de vida da sociedade, preservação e respeito com a biodiversidade, geração de renda e ecoeficiência (SACHS, 2009). A figura 01 ilustra as três principais dimensões da sustentabilidade, criada por John Elkington em 1990 com a nomenclatura de Tripé da Sustentabilidade, também conhecida por modelo Triple Bottom Linee, que simboliza um sincronismo necessário para conquistar o desenvolvimento sustentável de uma empresa, no tocante ao eixo social, econômico e ambiental correlacionada (DIAS, 2011).

Figura 01: Dimensões da Sustentabilidade.

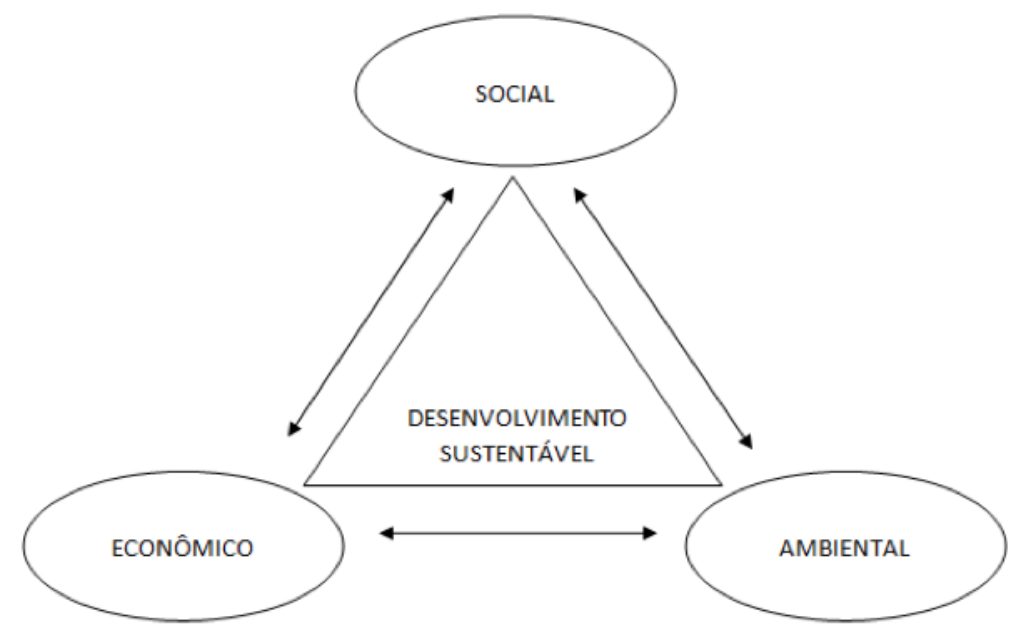

Fonte: Extraído de Dias (2011). 
A partir da figura 01 pode-se compreender que as dimensões são pilares necessários para uma empresa ou nação desenvolver de maneira sustentável, correlacionado uma com a outra, almejando inovações, equilíbrio entre produção e exploração de recursos naturais, reciclagem, lucratividade verde, inclusão social, valorização das comunidades, tecnologias ecoeficientes, energias renováveis, bens biodegradáveis e geração de empregos (DIAS, 2011).

Conforme Dias (2011) a dimensão econômica da sustentabilidade, provém das organizações no sentido de obter importância na atuação financeira, gerando concepções na qualidade de vida das pessoas, crescimento econômico com mentalidade no resultado do capital, mas com um olhar na preocupação ambiental e equilíbrio dos empreendimentos.

Neste contexto Sachs (2009) afirma que no crescimento econômico, necessita haver uma estabilidade entre os instrumentos de modernização, geração de renda, melhorias da economia e autonomia ao desenvolver uma estrutura equilibrada para a empresa, sociedade, governo e meio ambiente. Nobrega (2013) aponta a importância da dimensão econômica ao correlacionar a participação das empresas na economia de um país e na região onde a organização está inserida.

A dimensão econômica visa à lucratividade, proporcionando que empresas invistam em meios alternativos de produção, sem afetar a vida de toda uma biodiversidade, voltando ao controle entre produção e os recursos naturais disponíveis para este ato, discutindo ainda a criação de empregos e investimentos de capitais financeiros (SABINO, 2010).

Já a dimensão social da sustentabilidade, entende-se por a relação entre empresas e comunidades, com o respeito à diversidade, promoção da autonomia dos grupos sociais ou populacionais e desenvolvimento econômico do local onde a organização está situada. Para o autor, competem aos projetos voltados à responsabilidade social das empresas, tantos internos quanto externos, por exemplo, acolhendo os direitos fundamentais como o amparo aos menos favorecidos ou aos funcionários da organização (FREITAS, 2012).

Sachs (2009) relata que deve existir uma igualdade na distribuição de renda sendo da forma mais justa possível para as pessoas, por intermédio de serviços prestados, enfatizando a busca por uma qualidade de vida plena. Considerando as desigualdades como um problema que emerge na sociedade, tornam-se essenciais atitudes favoráveis que venham a contribuir para a minimização das dificuldades sociais, em especial nas comunidades carentes, salientando a 
viabilização de oportunidades empregatícias, combates as práticas de exclusão e construção da cidadania pelo governo e empresas (SILVA, SOUZA E LEAL, 2012).

Ainda sobre a dimensão social, Sabino (2010) destaca a inclusão de pessoas portadoras de necessidades especiais, negros, idosos, mulheres e GLBTs no ambiente de trabalho, apontando de um modo geral, a responsabilidade que as empresas possuem sobre cada funcionário, como a prestação de serviços médicos ou odontológicos, Equipamentos de Proteção Individual (EPIs), valorização e reconhecimento do trabalho, salários igualitários para homens e mulheres, comodidade, assistência psicológica e benefícios.

A iniciativa de criar projetos na comunidade seja por intermédio de ONGs, creches, distribuições de cestas básicas, prestação de serviços comunitários, assistência social e reformas de espaços públicos, contemplam a dimensão social nas empresas, na perspectiva de promover a cidadania ao provocar impactos positivos na sociedade (VEIGA, 2009).

A dimensão ambiental, na concepção de Dias (2011) ocorre quando empresas avaliam a qualidade dos processos produtivos, no que diz respeito a uma produção limpa, melhorias no desenvolvimento de um modelo sustentável, respeito ambiental e conservação dos recursos naturais. $\mathrm{O}$ autor pauteia que as organizações são responsáveis, em partes, pelos problemas ambientais, como poluição, desertificação, desmatamento e extinção de inúmeras espécies da fauna e flora.

Levando em conta as inúmeras intervenções governamentais, sociais e empresariais, para uma economia verde, sinaliza-se a importância de precaver as formas de ocupar áreas de proteção ambiental, consolidação de projetos voltados à ecoeficiência, preservação, reciclagem e prudência na criação de técnicas para manusear recursos para a produção atual, onde não esgote os recursos naturais existentes ou agrave a qualidade de vida das pessoas (SILVA, SOUZA e LEAL, 2012). De acordo com Freitas (2012) a responsabilidade ambiental já faz parte da missão de muitas organizações, porém poucas atividades voltadas a esta área são notórias, mesmo com os incentivos e benefícios da implementação de uma postura ecologicamente correta em uma empresa.

Para Sachs (2009) a dimensão ambiental entrelaça aspectos inerentes à qualidade dos produtos, intensificando em reduzir custos e desperdícios. Todavia o autor aponta que a maioria das organizações utiliza das dimensões da sustentabilidade para as campanhas de marketing, promovendo vendas ao referirem-se como amigas do meio ambiente, porém esta atitude não é 
de natureza errônea, ao analisar as contribuições destas empresas para o desenvolvimento sustentável.

Cada dimensão apresentada corresponde de maneira sincronizada a responsabilidades, benefícios e vantagens, quando implantadas em uma organização. As três dimensões da sustentabilidade, alinhadas ao cotidiano empresarial fornecem as empresas redução de custos, valorização dos funcionários e desenvolvimento socioeconômico e ambiental, relacionando-se aos benéficos previstos pela sustentabilidade empresarial (ALIGLERI, 2011).

\section{Sustentabilidade Empresarial}

Segundo Dias (2011) em 1992 aconteceu uma conferência no Rio de Janeiro, onde o conselho empresarial junto a empresários, discutiram ideias relevantes ao meio ambiente, resultante na elaboração de um documento relatando a importância sobre desenvolvimento sustentável voltado para o sentido empresarial. No começo do documento salientava que o mundo se movia em direção a desregulação nas iniciativas privadas e aos mercados globais, exigindo que as empresas assumissem responsabilidade social, econômica e ambiental ao definir papéis e ações administrativas.

O conselho empresarial mencionou que o desenvolvimento sustentável e de grande importância, uma vez que os empresários têm a possibilidade de criar novas oportunidades, melhorias do negócio e vantagens competividades no mercado em que atua, contudo para isso acontecer e preciso haver mudanças no comportamento organizacional, incluindo a ética socioambiental na forma de executar o negócio (DIAS, 2011).

Existem organizações que trabalham com práticas sustentáveis visando melhorias na qualidade de vida do meio ambiente, no entanto há aquelas que exercem atitudes ambientais por questões de obrigatoriedade legislativa ou percepções de marketing na mente do consumidor, mas vale ressalta que as empresas devem deixar de ser o problema e torna-se parte da solução em termos socioambientais (BARBIERI, 2011).

Barbieri (2011) defende que uma empresa sustentável é aquela que se preocupa com a sociedade, auxilia na resolução dos problemas ambientais, satisfazem as necessidades dos clientes, oferece renda justa para os funcionários e contribui para economia de um país. A figura 
02 sintetiza o modelo de uma empresa sustentável, uma vez que esteja em sintonia positiva com o governo, meio ambiente, sociedade e mercado.

Figura 02: Empresa Sustentável

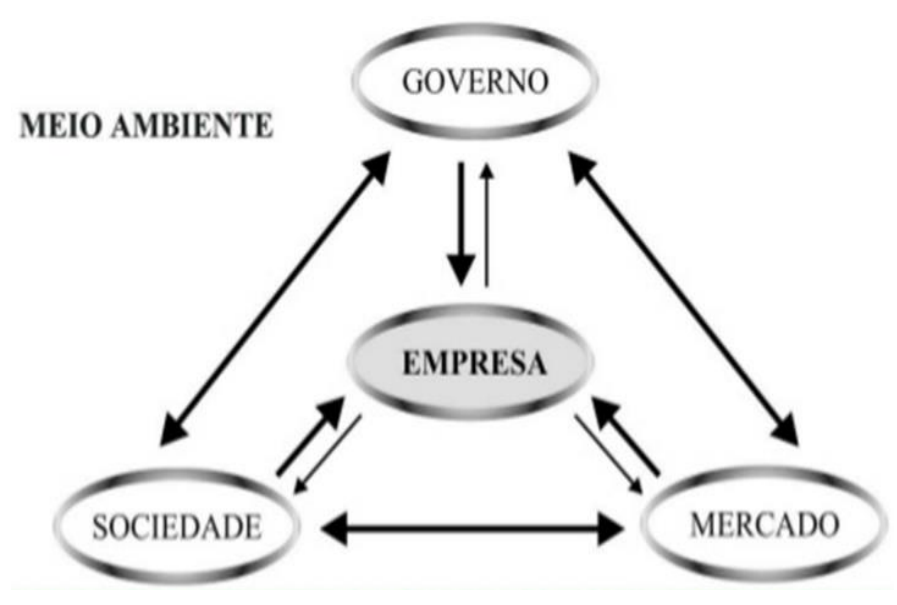

Fonte: Extraído de Barbieri (2011).

Uma empresa sustentável, segundo o modelo ilustrado na figura 02 é aquela que sentencia a mesma filosofia defendida pelo tripé da sustentabilidade ou Triple Bottom Linee, sincronizando as dimensões e alinhando as responsabilidades socioambientais com as funções administrativas, sendo esta função a essência da sustentabilidade empresarial (BARBIERI, 2011). O autor reforça que na figura 02 a empresa para ser sustentável necessita sincronizar as atividades econômicas com o meio ambiente, dentro de um meio dependente, ao passo de inserir no mercado produtos de qualidade sem tragam agraves a saúde das pessoas, possuir responsabilidades socioambientais na sociedade e atender a legislação do governo.

A sustentabilidade empresarial é definida como o equilíbrio entre as metas sociais, econômicas e ambientais, inter-relacionadas dentro do contexto organizacional (PHILIPPE, 2010). O conceito de sustentabilidade empresarial para Freitas (2012) induz a um novo modelo de gestão de negócios, levando em conta o conjunto de ações e decisões que uma organização toma, visando preservação ambiental, desenvolvimento da sociedade e o próprio crescimento econômico. 
Aligleri (2011) apresenta sustentabilidade empresarial como a geração de lucro para os acionistas, ao mesmo tempo em que protege a natureza e melhora a qualidade de vida das pessoas com quem mantém vínculo. Nobrega (2013) aponta que através de stakeholder, sistemas de gestão ambiental ou práticas sustentáveis, uma empresa pode se tornar sustentável e ainda obter vantagens competitivas, gerenciais e mercadológicas.

De acordo com Sabino (2010) a melhor forma de obter sustentabilidade empresarial é desenvolvendo práticas sustentáveis na organização, almejando impactos positivos na gestão socioambiental. Segundo o autor práticas sustentáveis são atitudes ecologicamente corretas voltada ao eixo ambiental, social e econômico, sendo altamente lucrativa nas empresas, pois auxiliam na redução de custos, fornecem ótimos canais de marketing, apresentam uma ótima imagem da empresa perante os consumidores, beneficia a sociedade uma vez que contribui para o bem-estar da comunidade onde a empresa reside e promove a geração de renda.

\section{Metodologia}

Este artigo contempla uma pesquisa de fonte bibliográfica, com natureza básica, abordagem qualitativa, exploratória e de cunho descritivo, levando em consideração a busca por informações sobre eventualidades debatidas na teoria e a delimitação de um campo para estudo (SEVERINO, 2016).

A pesquisa foi realizada em uma indústria alimentícia, localizada no centro da cidade de Juazeiro do Norte-CE desde 2006. A referida cidade soma uma população de 270.383 habitantes, tornando-a o terceiro mais populoso do Ceará, com distância de $491 \mathrm{~km}$ da capital Fortaleza. É importante pela figura do padre Cicero Romão Batista como um marco na construção da religiosidade, cultura do povo e acontecimentos históricos e políticos do Cariri, sendo considerada uma dos três maiores centros de religiosidade do Brasil, com grande polo cultural, centros de artesanato e cordel do nordeste do país, segundo dados do Instituto Brasileiro de Geografia e Estatística - IBGE (2016).

A indústria foi escolhida por acessibilidade, visto que o pesquisador excluiu indústrias alimentícias na qual não tinha acesso ou contato. A referida trabalha com a produção de alimentos derivados do milho, temperos e ervas para chás medicinais. $\mathrm{O}$ instrumento de coleta 
aconteceu em forma de observação assistemático não participante e entrevista, estruturada em roteiro com 20 questões abertas, aplicada ao gestor da indústria. Os dados coletados foram submetidos à análise de conteúdo, que constitui um método de pesquisa usado para descrever e interpretar dados de informações qualitativas (CRESWELL, 2010).

\section{Análise e Discussão dos Resultados}

Esta sessão apresenta a análise e interpretação dos dados obtidos na realização de uma entrevista com o gestor de uma indústria de alimentos, localizada na cidade de Juazeiro do Norte - Ceará no dia 02 de outubro de 2018.

As perguntas iniciais tinham o objetivo de compreender dados gerais sobre a empresa, nesse sentido, o gestor da indústria alimentícia, estudada neste artigo, pontuou que a referida empresa atua no mercado há 12 anos, possuindo onze funcionários, sendo oito internos e três externos. Trabalhando com a fabricação de derivados do milho, além de chás e condimentos alimentares. Apresentando um considerável mix de produtos, que englobam massas de milho para cuscuz e outros fins, colorífico também conhecido pelo nome popular de colorau, diversidade de temperos como pimentas e molhos, milho de mungunzá, fubá de milho, variedade de chás caseiros com propriedades medicinais e sementes para pássaros.

Foram realizadas perguntadas voltadas as três dimensões da sustentabilidade. As respostas dadas pelo gestor da indústria, no ato da entrevista, foram distribuídas em três esferas que contempla a análise perceptiva das dimensões da sustentabilidade.

A primeira esfera voltou-se a dimensão social, perguntado primeiramente se a indústria se preocupa em realizar uma distribuição de renda justa aos funcionários ou ações que fomente a qualidade de vida dos mesmos. Como resposta, identificou que há remuneração de acordo com a função executada na empresa, como também o pagamento de auxílio alimentação, saúde e curso para desenvolvimento das habilidades dos colaboradores. É visto então o foco no funcionário, um reconhecimento do serviço prestado. Foi indagado acerca dos EPIs (Equipamentos de Proteção Individual) que a empresa adota para os funcionários. Verificou-se que a empresa adota protetor auricular, luvas, protetor cervical, calçados adequados, luvas e máscara para respiração. 
Na sequência foi perguntado se a empresa estimula seus colaboradores e a comunidade na forma de pensar e agir, no que diz respeito a ser solidário, deixando responsabilidade ou legado positivo para gerações futuras. Identificou-se que a empresa alerta sobre o dever em tratar as pessoas dentro e fora da empresa de maneira correta e educada, da mesma forma como gostariam de ser tratados. Perguntado sobre quais os principais benefícios que a empresa apresentava tanto para o funcionário, quanto para a comunidade. Observou-se a preocupação com o bem-estar físico e mental dos colaboradores ao relatar a criação de vinculo harmônico com os mesmos. Na comunidade a preocupação está em atender bem os clientes de forma igualitária.

Foi indagado ao gestor se na indústria havia práticas no âmbito sociocultural ou parceira com ONGs, trabalhando em conjunto no desenvolvimento de algum programa que beneficie a comunidade. No entanto percebeu-se que não há nenhuma ação voltada a comunidade, sendo apresentada na resposta a inviabilidade de manter um projeto social, visto que a empresa é de pequeno porte.

Analisando, percebe-se que existe uma percepção social voltada ao funcionário da indústria, pautando pagamento de salário digno, estímulo ao desenvolvimento profissional, preocupação com a segurança no trabalho e benefícios, sendo esta ação favorável para a empresa, como confirma Freitas (2012), Sachs (2009) e Sabino (2010). Tendo em vista que o foco está no bem-estar do funcionário dentro da indústria.

Em relação à comunidade, verifica-se que há uma baixa existência de ações que visem à valorização social. Segundo o gestor, a indústria estimula as pessoas a pensar de maneira coletiva, solidária e igualitária, sendo que a mesma agrega isto aos seus clientes.

É notório que a indústria não dispõe de projetos sociais defendidas por Veiga (2009) e nem de práticas culturais com a comunidade. A justificativa apresentada pelo gestor sobre a não existência de programas sociais está no fato da indústria ser de pequeno porte, constatando dificuldade em elaborar algum projeto.

A dimensão social visa não somente o funcionário, mas também a comunidade, como uma forma de crescimento conjunto, a empresa mesmo de pequeno porte, pode desenvolver práticas simples, porém de suma importância para a comunidade, gerando impactos positivos ao melhorar a qualidade de vida da população como menciona Sabino (2010). 
Continuando a entrevista, foram questionadas as ações voltadas à dimensão econômica da sustentabilidade, no intuito de analisar as ações voltadas para geração de renda e contribuição com a economia local. Ao perguntar se a indústria buscava desenvolvimento econômico equilibrado, presando pela preservação do meio ambiente no tempo que desenvolve capacidade de modernização contínua em seus processos produtivos, presumiu-se que existe uma preocupação em preservar o meio ambiente, pois a indústria vem modernizando todos os processos de produção, visando melhorias sem afetar a natureza.

Houve a curiosidade em saber se a indústria desenvolvia pesquisas científicas e tecnológicas para melhoria do processo produtivo, como resposta, obteve a informação que realizavam estudos em inovação na produção para agregar qualidade aos produtos, possibilitando contribuir também com a economia local. Questionou-se a ocorrência de incentivos por parte do governo no desenvolvimento de práticas no âmbito econômico, verificou-se então que não nenhum tipo de incentivo.

Verifica-se ao analisar as respostas dada pelo gestor referente a dimensão econômica, que a indústria possui uma preocupação em desenvolver processos produtivos de maneira limpa, levando em consideração a ecoeficiência, apontada por Dias (2011). Visando melhorias na produção, a empresa estuda meios de inovar nos produtos para agregar qualidade ao cliente, firmando uma modernização que não afete ao meio ambiente. Este pensamento confirma as ideias de Silva, Souza e Leal (2012).

Em termos econômicos é nítido o desejo de contribuir com a economia local ao inserir uma produção limpa, segundo o gestor "planejamos gerar renda ao investir em tecnologias produtivas que sejam eficientes para a empresa, sem afetar a natureza". Observa-se a concepção do desenvolver sustentavelmente, como dita por Sachs (2009) e Philippe (2010).

A indústria não conta com incentivos de agentes governamentais para desenvolver práticas dentro do âmbito econômico no local a qual esta situada. Evidente que uma empresa para torna-se sustentável, necessita interagir com o poder governamental, como menciona Barbieri (2011), pois facilita acordos e benefícios para as organizações.

Prosseguindo com pesquisa, ocorreu o interesse de conhecer as ação relacionadas a dimensão ambiental da sustentabilidade, consistindo os aspectos inerentes às questões das práticas sustentáveis da indústria. Ao indagado se a empresa preservava o capital natural da 
produção ou limita o uso dos recursos não renováveis, ficou perceptível a preservação do capital natural, neste caso da principal matéria-prima que é o milho.

Foi perguntado se no processo produtivo de alimentos adicionava algum composto químico, por exemplo, conservante. Relatou o gestor que a empresa busca trabalhar apenas com produtos orgânicos de qualidade e com processos caseiros de fabricação, não adicionando nenhum tipo composto na produção, visando o melhor para o cliente. Em seguida houve um questionamento para saber como a empresa trata os resíduos sólidos, ou seja, todo o lixo que sobrava da produção. Notou-se que na indústria todo o material que sobra da produção e selecionado, tratado e vendido como subproduto. Perguntado se a empresa realizava coletava ou separação seletiva, o gestor pontuou que o lixo é separado e enviado para empresas responsáveis pela coleta e reciclagem.

Percebe-se nitidamente que a dimensão ambiental está bem presente na indústria, comparando com a social e econômica. A responsabilidade socioambiental é perceptível na preocupação em fornecer produtos de qualidade ao cliente, sem mistura de compostos químicos, inserindo no mercado bens orgânicos. O milho é a principal matéria-prima, por isto o gestor aponta a preservação deste capital natural.

Na perspectiva das práticas sustentáveis, defendidas por Sabino (2010) como vínculo na obtenção da sustentabilidade, a indústria desenvolve duas voltadas à destinação dos resíduos sólidos, passando pela seleção e tratamento deste, dependendo do tipo. Percebe-se na dimensão ambiental, como também na econômica, a qualidade em ênfase, presumindo uma responsabilidade de ofertar ao mercado produtos de qualidade, em conformidade à sustentabilidade, confirmando o pensamento de Dias (2011) e Aligleri (2011).

A indústria pode se utilizar destas responsabilidades socioambientais e das práticas sustentáveis nas campanhas de marketing, sendo uma forma de passar credibilidade ao consumidor, como Sachs (2009) aponta. Foi perguntado ao gestor se havia divulgações das ações executadas nas três dimensões da sustentabilidade, notou-se que não existem quaisquer tipos de divulgação.

Houve um questionamento sobre quais as dificuldades que a indústria enfrentava para desenvolver ou manter algum programa que abrange as dimensões. Como resposta, foi apresentada que a "empresa não consegue encontrar pessoas que desenvolva tais programas que visam ajudar o próximo sem fins lucrativos". O gestor acrescenta a colaboração em doações de 
produtos para montarem cestas básicas, não sendo esta uma ação pertinente à empresa, mas de terceiros.

A indústria em estudo já compreende sobre as ações pertinentes as dimensões, com base na análise das ações desenvolvidas, porém é necessário criar uma sincronia entre a empresa, sociedade, governo e mercado, tendo em vista a implantação de uma postura sustentável, com base empresarial, mencionada por Barbiere (2011) e Freitas (2012).

\section{Considerações Finais}

Quando se fala em sustentabilidade empresarial, muitos compreendem por ações relacionadas somente ao meio ambiente, no entanto, pode-se afirmar que a sustentabilidade contempla dimensões que estão interligadas a três aspectos, como social, econômico e ambiental, transparecendo a ideologia de melhorias no âmbito organizacional, na qualidade de vida e preservação dos recursos naturais.

Percebe-se que desenvolvimento sustentável é aquele que utiliza dos recursos naturais presente, sem afetar as condições de existência destes referidos, recursos no futuro. Com isto alinhado as empresas, pode fornecer redução de custos, vantagens competitivas, melhorias da qualidade de vida do colaborador, inclusão social, redução de impactos ambientais, geração de renda, desenvolvimento socioeconômico e contribuição social.

A problemática deste estudo foi respondida por meio do objetivo geral, relacionando as dimensões da sustentabilidade com as práticas produtivas de uma indústria de alimentos na cidade de Juazeiro do Norte-CE. Verificando cada ponto previsto nas dimensões com a realidade fabril. Notou-se que na indústria estudada, trabalha de maneira parcial a ocorrência das três dimensões. Sendo que há um destaque especial para a dimensão social voltada ao funcionário, percebendo que a empresa visa à qualidade de vida e o bem-estar dos colaboradores. Na econômica as ações estão voltadas a lucratividade da empresa. Já a ambiental está bem presente na indústria, no sentido de responsabilidade e ecoeficiência, além do desejo de entregar aos clientes produtos de qualidade e livre de químicas. 
Em relação aos objetivos específicos, identificou as práticas ambientais da indústria, embora poucas. Apresentou as dimensões da sustentabilidade propostas por Sachs e analisou a performance da indústria alimentícia na perspectiva da sustentabilidade empresarial.

A empresa necessita melhorar suas ações voltadas à sustentabilidade, adotando uma postura ou estratégias que englobe cada dimensão, visando às vantagens que podem ser proporcionadas para a empresa, comunidade e meio ambiente. Adequando-se também as normas ambientais e de produção limpa.

Tendo em vista que este estudo se limitou a uma indústria do ramo alimentício, a fim de conhecer as dimensões da sustentabilidade aplicadas, surge à curiosidade de entender como outras indústrias de ramos diferentes, dentro da cidade de Juazeiro do Norte-CE, aplicam as dimensões ao contento empresarial.

\section{Referências}

ALIGLERI, Lilian Mara. Adoção de Ferramentas de Gestão para a Sustentabilidade e a sua Relação com os Princípios Ecológicos nas Empresas. p. 178. Tese de Doutorado: Universidade de São Paulo, 2011.

BARBIERI, José Carlos. Gestão Ambiental Empresarial: Conceitos, Modelos e Instrumentos. 2. ed. São Paulo: Saraiva, 2011.

CRESWELL, John. Projeto de Pesquisa: Métodos Qualitativo, Quantitativo e Misto. 3. ed. Porto Alegre: Artmed, 2010.

DIAS, Reinaldo. Gestão Ambiental: Responsabilidade Social e Sustentabilidade. 2. ed. São Paulo: Atlas, 2011.

FREITAS, Juarez. Sustentabilidade: Direito ao Futuro. 2. ed. Belo Horizonte: Fórum, 2012.

IBGE. População e Características Físicas de Juazeiro do Norte - Ceará. Disponível em: $<$ https://cidades.ibge.gov.br/brasil/ce/juazeiro-do-norte/panorama>. Acesso em: 15 abr. 2018.

PHILIPPI, Luiz Sérgio. A Construção do Desenvolvimento Sustentável. 3. ed. São Paulo: Manole, 2010.

NOBREGA, Ribeiro. Práticas Sustentáveis. 1. ed. João Pessoa: Moura Ramos, 2015. SABINO, Alex. Práticas Sustentáveis nas Empresas. 1. ed. Olinda: Livro Rápido, 2010. 
SACHS, Ignacy. Caminhos para o Desenvolvimento Sustentável. 2. ed. Rio de Janeiro: Garamond, 2009.

SEVERINO, Antônio Joaquim. Metodologia do Trabalho Científico. 24. ed. São Paulo: Cortez, 2016.

SILVA, Antônio Sergio; SOUZA, José Gilberto; LEAL, Antônio Cezar. A Sustentabilidade e suas Dimensões como Fundamento da Qualidade de Vida. Artigo Científico, v. 1, n. 12, p. 2242: Presidente Prudente, 2012.

SOUZA, G. R., CORDEIRO, J. S. Mapeamento Cognitivo e Balanced Scorecard na Gestão Estratégia de Resíduos Sólidos Urbanos. Gestão da Produção, v. 17, n. 3, p. 483-446, 2010.

VEIGA, José Eli. Desenvolvimento Sustentável: O Desafio do Século XXI. 1. ed. Rio de Janeiro: Garamond, 2009.

\section{Como citar este artigo (Formato ABNT):}

SINEIS, Edina de Oliveira; ALBUQUERQUE, Joyce da Silva. As Dimensões da Sustentabilidade Aplicadas em uma Indústria de Alimentos na Cidade de Juazeiro do Norte-CE. Id on Line Rev.Mult. Psic., 2018, vol.12, n.42, p. 743-760. ISSN: 1981-1179.

Recebido: 19/10/2018;

Aceito: $22 / 10 / 2018$ 